\title{
Value and Size Effects in the Stock Market of the Philippines
}

\author{
Gerardo "Gerry" Alfonso Perez" \\ ${ }^{1}$ Universidad de Granada, Granada, Spain \\ Correspondence: Gerardo "Gerry” Alfonso Perez, Universidad de Granada, Granada, Spain.
}

Received: March 12, 2018

Accepted: March 26, 2018

Online Published: March 30, 2018

doi:10.5430/ijfr.v9n2p191

URL: https://doi.org/10.5430/ijfr.v9n2p191

\begin{abstract}
Several market abnormalities, such as the small size effect or the value effect, have been found in the stock markets across the world. In this article it is analyzed the case of the stock market of the Philippines. The Philippines, while having a relatively large economy and a capital market with long history, has attracted less research than other Asian countries, such as China or Japan. This is perhaps due to the much larger size of the economies and capital markets of those countries. Nevertheless the stock market of the Philippines is important enough to warrant attention. It will be shown that in recent years there is no indication of a value effect or a small size effect in the stock market of the Philippines, which is surprising given the amount of articles finding such results in other countries. The results were consistent when using the entire dataset as well as when comparing each year individually. It was also found, using weekly returns, that value and growth stocks as well as small and large companies present volatility clustering, which is a result more consistent with the existing literature in other markets. There are less evidence of volatility clustering when using monthly returns rather than when using weekly returns.
\end{abstract}

Keywords: value investing, size effect, Philippinnes

\section{Introduction}

The capital markets of the Philippines has attracted much less attention than some of its South Asian neighbors despite having a relatively large, at least for South Asia standards, open economy that has grown at elevated rates over a long period of time as well as an independent central bank and a relatively modern stock exchange. The low amount of research covering the stock market in the Philippines might be related to its proximity to some countries with massive economies such as China and Japan. Both of these countries have capital markets substantially bigger than the one in the Philippines that are likely to attract more interest by scholars and practitioners. The economy of the Philippines has had ups and downs but in recent years there have been signals of improvement. The Philippines is currently classified by the World Bank as a lower middle income country with a GPD per capita of roughly 2,951 USD, up 2.5\% from the 2015 level (unless otherwise indicated all the macro figures were obtained from the World Bank). The country experienced a significant demographic expansion in recent decades with the population increasing a 66.6\% from 1990 (61.95 million habitants) to 103.32 in 2016 with the mortality of infants (under 5) decreasing to 27 per 1,000 births in 2016 from a value of 58 in 1990. Some authors, such as (Fukuoka, 2010) have mentioned that the positive economic development of the country has helped the population expanding (finding a statistically meaningful causal relationship). There are also some indications of improvements in efficiency in the economy with for instance the average time for opening a new business decreasing from 49 days on average in 2000 to 28 in 2016. Domestic credit from financial institutions has also expanded substantial reaching $63.5 \%$ of total GDP in 2016 from the arguably low rate of $23.2 \%$ in 1990.

Given the size of the economy in the Philippines and its economic rates as well as the complexities and idiosyncrasies in the country it seems interesting to analyze if the stock market abnormalities presented in other countries are also present in the Philippines. Extrapolating the results regarding market abnormalities into such a complex and arguably unique emerging market such as the Philippines could lead to wrong conclusions. As emerging market economies become more and more relevant globally the importance of understanding their capital market also increases.

\subsection{Brief Introduction to the Economy of the Philippines}

An in depth analysis of the economy of the Philippines is beyond the scope of this article but it is important nevertheless to discuss some of the main features and peculiarities of this economy that in turn could influence the 
performance of its stock market. The World Bank ranked the Philippines in 2016 in the 36 position in the rank of nominal GDP per country with a total GDP of approximately USD 305 billion that year. There are a few common misconceptions regarding the economy of the Philippines. For instance, house hold consumption is for South Asia standards sizeable. According to figures from the Philippine Statistics Authority household consumption as a percentage of GDP has remained roughly unchanged in the 2015 to 2017 period, with a value just above $73 \%$. Another common misconception about the Philipines is that its economy remains agricultural based. The Philippines over the years has tried to modernize its economy with the agriculture sector (including fishing activities) only accounting for 9.6\% of GDP in 2017 (current prices) according to figures from the Philippine Statistic Authority (PSA, 2018). While the contribution of agriculture to GDP is not too large some scholars, such as (Cielito, 2005), have highlighted the importance of the sector as a major employer. Overall underemployment was estimated at 18.5 percent in 2015 by the central bank of the Philippines. The main contributor of GDP is the service sector accounting for 58.8\%, 59.5\% and 59.8\% respectively in 2015, 2016 and 2017 with industry accounting for 30.9\%, 30.8\% and $30.6 \%$ during the same period. The transformation from an agricultural economy into a services economy without the step of the industrialization process has been mentioned by several authors, such as (Ofreneo, 2014). The same author mentioned the importance of overseas remittances in this process. There are several articles describing the importance of these overseas remittances in several areas such as social mobility (Ducanes, 2015) and business cycles (Renato, 2009). It seems clear that the Filipino diaspora has helped brining substantial capital into the country. These set of economic features make the Philippines a rather unique country with some very idiosyncratic characteristics.

\subsection{Central Bank, Stock Exchange and Regulator}

The Philippines has a relatively modern financial market including an independent central bank and stock exchange that uses some infrastructure from developed markets such as the U.S. and an independent regulator entrusted with the supervision of the market as well as registration approvals.

The Bangko Sentral ng Pilipinas is the central bank of the Philippines and loosely resembles the U.S. Federal Reserve in its structure. The role of the Bangko Sentral ng Pilipinas is reflected in the constitution, section 29, article XII (BSP, 2015). The mandate of the Bangko Sentral ng Pilipinas is: 1) to maintain price stability, 2) to maintain financial stability and 3) to ensure a smooth payment and settlement of financial transactions (BSP, 2015). Some authors, such as (Lim, 2008) have described the policies of the central bank as benign. Clearly there are also less favorable views of the performance of the central bank but overall it seems that it is run in a professional way particularly when considering that it is the central bank of a developing market.

The Philippine Stock Exchange has been in operation since early 1994 (Regina, 2013) after the merger of two pre-existing stocks exchanges. Overall the Philippines, perhaps due to the influence of the U.S. during the colonial period, has one of the oldest stock exchanges operating in a modern way. The stock exchange of the Philippines has invested significantly in infrastructure over the years, for instance acquiring a trading system from NASDAQ OMX in 2014 (RP, 2014).

The Securities and Exchange Commission of the Philippines (SEC) is the main regulator of the stock market (SEC, 2018) and similarly to the case of the central bank is inspired on its U.S. counterparty. The SEC has a broad set of powers ranging from supervision, registration approval to enforcement (SEC, 2018). (SEC, 2018) in the enforcement side the SEC can levy sections against institutions that it considers that have breached some existing rules and/or regulations. The beginning of the SEC date back to 1936 Commonwealth Act 83 (SEC, 2018). At this time the Philippines was still under the colonial rule of the U.S.

One of the frequently mentioned shortcomings of the overall financial system in the Philippines is the issue of financial inclusion (Llanto, 2015) with a sizeable part of the population not able to participate on the financial sector due to low income and wealth. In a related topic (Habaradas, 2013) mentioned the expansion in recent years of microfinance and its coverage of a segment of the population with low economic resources.

\subsection{Philippines Stock Market}

The Philippines is a large a complex country and such complexity is reflected in its stock market. It has been mentioned by some scholars, such as (Sy, 2014) that the stock market in the Philippines is prone to experience periods of high volatility, that might be caused among many other factors for relatively low financial education among many individual investors as well as by the normal business of an open emerging market economy. (Bautista, 2016) identified several periods of high volatility in the stock market related to major developments such as military cups in the eighties. 
While the Philippines has relatively modern institutions there are some issues in its capital market. For instance, compared to global standards trading in the Philippines is not cheap with minimum brokerage commission levels (see table 1) and a recent increase in trading taxes. The increase in trading taxes is part of an overall effort by the country to rise more funds and it is a part of the "Tax Reform For Acceleration and Inclusion (TRAIN) Act" approved in late December 2017 (DOF, 2017). This program is intended to raise capital for social programs and has a multitude of components ranging from tax cuts differentiating tourist and non-tourist economic areas as well as more taxes on tobacco. Included in this tax package there is a $20 \%$ increase in stock transaction taxes. This increase in trading taxes has received some criticism with for instance the head of the Philippine Stock Exchange quoted in the media mentioning concern of making the Philippines stock market "uncompetitive" compared to some of its regional peers (MT, 2017).

Table 1. Some trading costs in the Philippines

\begin{tabular}{ll}
\hline Item & Cost \\
\hline Minimum brokerage commission & $0.25 \%$ \\
Previous transaction tax (until 2017) & $0.50 \%$ \\
New Transaction tax (effective January 2018) & $0.60 \%$
\end{tabular}

Sources: (Abola, 2016), (DOF, 2017)

There are also many social peculiarities that might cause differences in equity behaviors in the Philippines compared to other countries. For instance, (Kalayaan, 2016) mentioned that the performance of the stock market is impacted by cultural superstition with some investors considering Friday $13^{\text {th }}$ unlucky. According to this article even some investors that do not believe in such superstition acknowledge the impact of such believes in the stock market. The basic idea is that no matter if the investors believe in unlucky days or not he/she has to take into account the reality of many individual investors believing in such effects and therefore having an influence in the market.

Being an open economy with a sizeable exports industry the Philippines is impacted by developments in overseas markets. This economic openness might also have some impact on the behavior of the stock market. (Kuo-Jui, 2012) showed that the performance of the stock market in the Philippines is impacted by the exchange rate with the USD. Similarly (Sum, 2013) mentioned that policy uncertainty in the U.S. has a negative impact on the performance of the stock market in the Philippines. The U.S. due to its size and historical connections seems to have a particular large impact on the Philippines. It should be noted that some scholars have found less of an impact of trade openness in the capital market of the Philippines with (Lida, 2016) concluding that the impact on volatility due to trade openness was not significant for the entire time series that the author used. However (Lida, 2016) did found some statistically significant influence of trade openness in stock market volatility in some of the data subsets.

Another relatively recent development in the Philippines equity market that is worth of attention is the proliferation of online trading platform developed by brokerage firms to entice trades from individual investors. One interesting article in this regard is (Chua, 2014). According to the results from this article online trading platform appear to be a convenient a relatively easy to use tool attracting mostly male investors with only limited financial knowledge. This is clearly not unique to the Philippine market with such services being offered in many developed and developing countries but it could nevertheless have an impact on stock returns. Stock market activity in the Philippines has remained relatively high (figures 1 and 2).

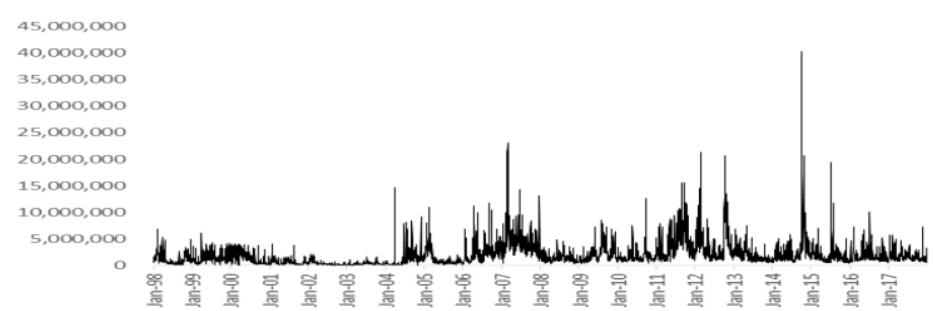

Figure 1. Daily number of shares (thousands) traded in the Phillipies Stock Exchange (Volume) 


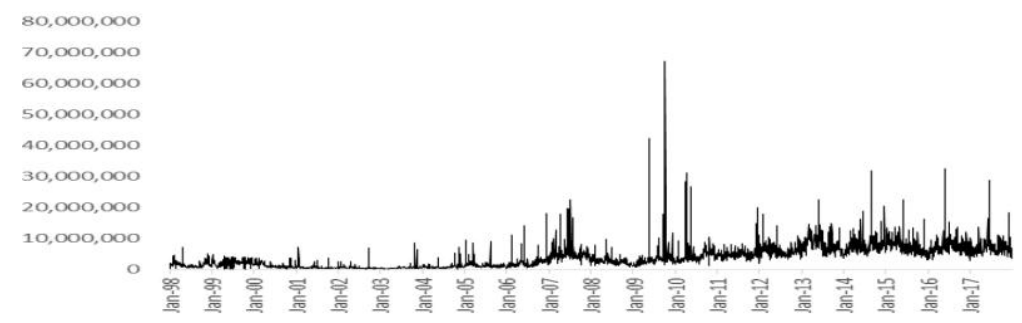

Figure 2. Daily turnover traded in the Phillipies Stock Exchange (thousand pesos)

\subsection{Impact of Natural Disasters}

The Philippines due to their geographical location in the Ring of Fire is prone to natural disasters such as typhoon Yolanda in 2013. Other natural disasters affecting the Philippines stock market relatively frequently mentioned in the literature are (Galido, 2013) volcanoes, tsunamis and earthquakes. (Galido, 2013) mentioned the possibility of the existence of a "gaining from loss" type of situation. In simple terms this idea suggests that a natural disaster can potentially have positive effects for the stock market typically linked to the reconstruction efforts. This idea was first proposed, for other markets, by (Shelor, 1992). In the case of the previously mentioned typhoon Yolanda the economic impact, according to the World Bank (WB, 2014), was less than expected. Natural disasters are clearly not exclusive of the Philippines but given their frequency and their potential distortions on stock performance it is important to keep them in mind and yet another factor that could have an impact on stock returns.

\subsection{Market Abnormalities}

In this context market abnormalities are understood as stock return behaviors that appear to have a difficult explanation or that appear to contradict the efficient market hypothesis. The underlying base assumption is that market, at least to some degree, are efficient and hence it is unlikely to find trading strategies that outperform on an ongoing and risk adjusted basis. An example of this market abnormality could be value investing. If stocks that fall in the value bucket outperform on a consistent basis then this could be, and has been, used as an argument against the efficient market hypothesis. There are opposing views in the literature regarding if the outperformance of value stocks is a valid argument against market efficiency or if it is just a result of mispricing risk.

\subsection{Value and Size Effects}

The value effect is the observation in some market of an outperformance of value stocks that loosely speaking could be described as those that have low valuations following ratios such as $\mathrm{P} / \mathrm{E}$ or $\mathrm{P} / \mathrm{B}$. The value effect appears to be dependent of the country/region analyzed as well as the time period. Some very well-known investors such as Warren Buffet are advocates of this style of investing with the work of Benjamin Graham (Graham, 1949) frequently quoted as one of the most influential and earliest analysis on the issue. A very important academic article covering value investing is (Basu, 1977). In that article the author identified a relationship between P/E values and stock performance which it is at the base of value investing. It should be noted that if markets are fully efficient then finding a subset of discernible stocks that consistently outperform the market should not be possible. A common counterargument to this observation is that market abnormalities arise from models misspecifications rather than by the market not being efficient (Banz, 1981). A strategy that it is typically analyzed as a juxtaposition of value investing is growth investing. Growth investing is based on the concept of investing in companies that have experienced or are about to experience high rates of growth. This usually translates into selecting stocks that have high valuations. The value and growth universes tend to be rather distinct with stocks typically not categorized simultaneously as growth and value stocks.

Another frequently mentioned market abnormality in the literature is the observed fact in some markets that the stocks of small companies tend to outperform the returns of larger companies. This was first identified for the U.S. market and has since then being observed in several other countries. The reasons behind this effect are not as well understood as in the case of other market abnormalities such as the value effect, which have a very solid of work suggesting possible explanations. (Banz, 1981) is frequently referred as one of the most important papers analyzing the small capitalization effect with the author concluding that companies with smaller total market capitalization tended to have higher risk adjusted returns that those of larger companies. In that article the author analyzed companies listed in the New York Stock Exchange. 


\subsection{Objectives}

Given the peculiarities of the stock market in the Philippines it seemed interesting to analyze if it follows some market abnormalities found in another markets. More specifically in this article it is attempted to determine if there is a value effect in the stock market of the Philippines. Another market abnormality that will be analyzed is the size effect in an attempt to determine if small listed stocks perform statistically better than stocks of bigger companies. Another objective is to determine if there is volatility clustering present in the style and/or size indexes.

\section{Methodology}

\subsection{Data}

The Philippines MSCI Value and MSCI Growth indexes (figure 4) were used as a representative of these two trading strategies. The Philippines Stock Exchange PSEi Index was used as the proxy for the Philippines overall market. End of month index data was obtained from Bloomberg and then was transformed into monthly returns. The time series encompasses the period from 1998 to 2017.

Similar approach (figure 3) was followed for the size style with the Philippines MSCI Small Cap, MSCI Philippines Medium Cap and the MSCI Philippines Small cap used as proxies for small, medium and large caps respectively. The time series for these indexes is shorter ranging only from 2008 to 2017. As in the case of the value indexes the end of month size indexes were obtained from Bloomberg and then transformed into monthly returns. The risk free rate used to determine the risk adjusted returns was the yield on the 10-year government bond from the Philippines. The data was obtained from Bloomberg. Risk adjusted returns have a shorter time series due to the oldest available risk free available from the data provider dating back to 2008 .

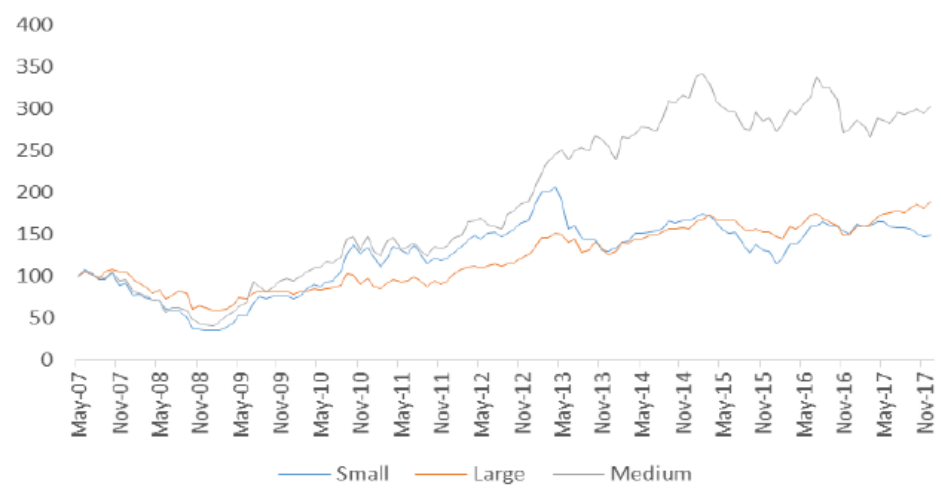

Figure 3. Performance (normalized) of size indexes in the Philippines

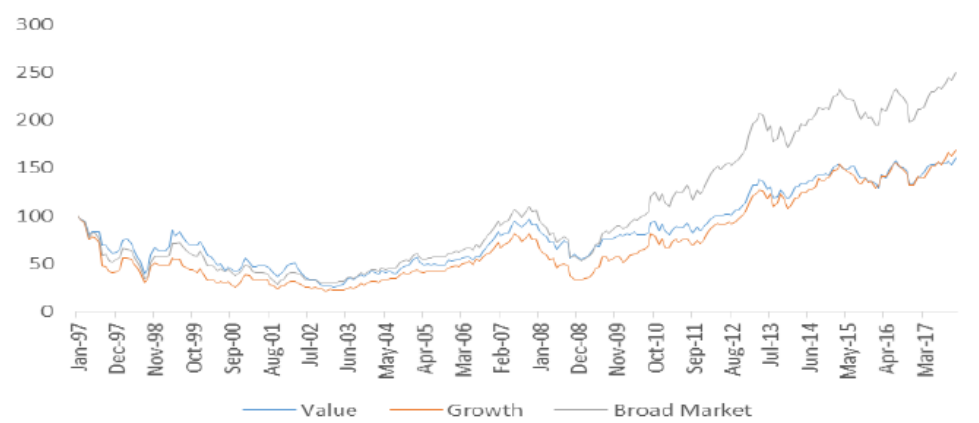

Figure 4. Performance (normalized) of value indexes in the Philippines

\subsection{Methods}

The monthly returns of the value, growth and overall market indexes were compared using a Wilcoxon rank sum test and a Kruskal Wallis test. The tests were performed using the entire data set available as well as each year independently. The results of these tests can be found in tables 2 to 9 . No further modification of the data was 
performed. There were end of month data for all the periods analyzed and hence there was no need to do data interpolation. All these tests are non-parametric tests that do not assume that the stocks returns follow a normal distribution. There is abundant literature supporting the idea that stocks returns do not follow a normal distribution. The null hypothesis in the Wilcoxon Rank Sum test is that the data come from distributions with the same median. The Kruskal Wallis test formally compares the data in each category to determine if they come from the same distribution. Data coming from the same distribution is the null hypothesis of this test. The results of both tests are consistent with each other pointing towards no statistically appreciable value outperformance of value stocks or small size stocks during the entire period analyzed or for each of the calendar years.

As previously mentioned the volatility clustering effect was analyzed during weekly returns, see figures 5 and 6 , as well as (for consistency purposes with the previous section) with monthly returns. The returns of the style and size indexes were tested for volatility clustering using a Ljung-Box Qtest. The usual approach of 5 and 10 lags was used. The results can be seen in tables 10 to 13 . The null hypothesis of the Ljung-Box Qtest is that there is no volatility clustering (residuals are not autocorrelated).

Table 2. Wilcoxon rank sum tests for style indexes (1998-2018)

\begin{tabular}{lll}
\hline Indexes & $\mathrm{p}$ & $\mathrm{H}$ \\
\hline Value-Growth & 0.5339 & 0 \\
Value-Broad market & 0.5158 & 0 \\
Growth-Broad market & 0.9060 & 0 \\
\hline
\end{tabular}

Table 3. Wilcoxon rank sum tests for size indexes (2008-2018)

\begin{tabular}{lll}
\hline Indexes & $\mathrm{p}$ & $\mathrm{H}$ \\
\hline Large-Medium & 0.6859 & 0 \\
Large-Small & 0.7162 & 0 \\
Large-Broad market & 0.6561 & 0 \\
Medium-Small & 0.5438 & 0 \\
Medium- Broad market & 0.9341 & 0 \\
Small- Broad market & 0.4408 & 0 \\
\hline
\end{tabular}

Table 4. Kruskal Wallis for style indexes (1998-2018)

\begin{tabular}{lll}
\hline Indexes & $\mathrm{p}$ & $\mathrm{H}$ \\
\hline Value-Growth & 0.5333 & 0 \\
Value-Broad market & 0.5152 & 0 \\
Growth-Broad market & 0.9053 & 0 \\
All simultaneously & 0.7609 & 0 \\
\hline
\end{tabular}

Table 5. Kruskal Wallis tests for size indexes (2008-2018)

\begin{tabular}{lll}
\hline Indexes & $\mathrm{p}$ & $\mathrm{H}$ \\
\hline Large-Medium & 0.6852 & 0 \\
Large-Small & 0.7155 & 0 \\
Large-Broad market & 0.6554 & 0 \\
Medium-Small & 0.5431 & 0 \\
Medium- Broad market & 0.9333 & 0 \\
Small- Broad market & 0.4403 & 0 \\
All simultaneously & 0.8678 & 0 \\
\hline
\end{tabular}


Table 6. Wilcoxon rank sum tests for style indexes per year

\begin{tabular}{lllllll}
\hline Year & \multicolumn{2}{l}{ Value - Growth } & \multicolumn{2}{c}{ Value - Market } & \multicolumn{2}{l}{ Growth- Market } \\
\hline & $\mathrm{p}$ & $\mathrm{H}$ & $\mathrm{p}$ & $\mathrm{H}$ & $\mathrm{p}$ & $\mathrm{H}$ \\
\hline 1998 & 0.9770 & 0 & 0.9310 & 0 & 1.0000 & 0 \\
1999 & 0.8399 & 0 & 1.0000 & 0 & 0.6650 & 0 \\
2000 & 0.9310 & 0 & 1.0000 & 0 & 0.9770 & 0 \\
2001 & 0.8852 & 0 & 0.7950 & 0 & 0.8852 & 0 \\
2002 & 0.4705 & 0 & 0.4025 & 0 & 0.7508 & 0 \\
2003 & 0.7508 & 0 & 0.8852 & 0 & 0.9770 & 0 \\
2004 & 0.8852 & 0 & 0.9310 & 0 & 0.9310 & 0 \\
2005 & 0.7508 & 0 & 0.7508 & 0 & 0.7950 & 0 \\
2006 & 0.8399 & 0 & 0.9310 & 0 & 0.9310 & 0 \\
2007 & 0.9310 & 0 & 0.8399 & 0 & 0.9770 & 0 \\
2008 & 0.4025 & 0 & 0.6236 & 0 & 0.7075 & 0 \\
2009 & 0.8399 & 0 & 0.5834 & 0 & 0.9770 & 0 \\
2010 & 0.4025 & 0 & 0.2145 & 0 & 0.7508 & 0 \\
2011 & 0.9770 & 0 & 0.7075 & 0 & 0.7580 & 0 \\
2012 & 0.8399 & 0 & 0.9770 & 0 & 0.7950 & 0 \\
2013 & 0.9310 & 0 & 0.8852 & 0 & 0.8399 & 0 \\
2014 & 0.5067 & 0 & 0.8399 & 0 & 0.8852 & 0 \\
2015 & 0.8399 & 0 & 0.9310 & 0 & 0.9770 & 0 \\
2016 & 0.9770 & 0 & 0.9310 & 0 & 0.8852 & 0 \\
2017 & 0.7950 & 0 & 0.6650 & 0 & 0.8399 & 0 \\
\hline
\end{tabular}

Table 7. Wilcoxon rank sum tests for size indexes per year

\begin{tabular}{ccccccc}
\hline Year & Large-Mid & Large-Small & Large-Market & Mid-Small & Mid-Market & Small-Market \\
\hline 2008 & 0.7508 & 0.5067 & 0.5485 & 1.0000 & 0.7950 & 0.5444 \\
2009 & 0.1939 & 0.3123 & 0.2855 & 0.7075 & 0.2145 & 0.9770 \\
2010 & 0.3408 & 0.1749 & 0.4025 & 0.7508 & 0.5384 & 0.3708 \\
2011 & 0.7075 & 0.8399 & 0.7075 & 0.9770 & 0.6236 & 0.6236 \\
2012 & 0.8852 & 0.5067 & 0.9770 & 0.6236 & 0.9310 & 0.6650 \\
2013 & 0.3708 & 0.4705 & 1.0000 & 0.1572 & 0.3408 & 0.4357 \\
2014 & 0.5067 & 0.8399 & 0.8399 & 0.6236 & 0.7950 & 0.8399 \\
2015 & 0.4025 & 0.9526 & 0.7950 & 0.5834 & 0.6236 & 0.3708 \\
2016 & 0.9770 & 0.5444 & 0.9770 & 0.5444 & 0.9310 & 0.6236 \\
2017 & 0.3708 & 0.0606 & 0.8399 & 0.5067 & 0.2366 & 0.0464 \\
\hline
\end{tabular}

Table 8. Kruskal Wallis tests for style indexes per year

\begin{tabular}{lcccc}
\hline Year & Value-Growth & Value-Index & Growth-Index & All \\
\hline 1998 & 0.9540 & 0.9081 & 1.0000 & 0.9978 \\
1999 & 0.8174 & 1.0000 & 0.6442 & 0.9194 \\
2000 & 0.9081 & 1.0000 & 0.9540 & 0.9978 \\
2001 & 0.8625 & 0.7728 & 0.8625 & 0.9531 \\
2002 & 0.4529 & 0.3865 & 0.7290 & 0.6199 \\
2003 & 0.7290 & 0.8625 & 0.9540 & 0.9509 \\
2004 & 0.8625 & 0.9081 & 0.9081 & 0.9844 \\
2005 & 0.7290 & 0.7290 & 0.7728 & 0.9050 \\
\hline
\end{tabular}




\begin{tabular}{lllll}
\hline 2006 & 0.8174 & 0.9081 & 0.9081 & 0.9792 \\
2007 & 0.9081 & 0.8174 & 0.9540 & 0.9858 \\
2008 & 0.3865 & 0.6033 & 0.6861 & 0.6707 \\
2009 & 0.8174 & 0.5637 & 0.9540 & 0.8928 \\
2010 & 0.3865 & 0.2040 & 0.7290 & 0.4605 \\
2011 & 0.9540 & 0.6861 & 0.7290 & 0.9091 \\
2012 & 0.8174 & 0.9540 & 0.7728 & 0.9552 \\
2013 & 0.9081 & 0.8625 & 0.8147 & 0.9770 \\
2014 & 0.4884 & 0.8174 & 0.8625 & 0.8345 \\
2015 & 0.8174 & 0.9081 & 0.9540 & 0.9770 \\
2016 & 0.9540 & 0.9081 & 0.8625 & 0.9858 \\
2017 & 0.7728 & 0.6442 & 0.8174 & 0.9050 \\
\hline
\end{tabular}

Table 9. Kruskal Wallis tests for size indexes per year

\begin{tabular}{ccccccc}
\hline Year & Large-Mid & Large-Small & Large-Market & Mid-Small & Mid-Market & Small-Market \\
\hline 2008 & 0.7290 & 0.4884 & 0.5637 & 1.0000 & 0.7728 & 0.5254 \\
2009 & 0.1842 & 0.2987 & 0.2727 & 0.6861 & 0.2040 & 0.9540 \\
2010 & 0.3263 & 0.1659 & 0.3865 & 0.7290 & 0.5637 & 0.3556 \\
2011 & 0.6861 & 0.8174 & 0.6861 & 0.9540 & 0.6033 & 0.6033 \\
2012 & 0.8625 & 0.4884 & 0.9540 & 0.6033 & 0.9081 & 0.6442 \\
2013 & 0.3556 & 0.4529 & 1.0000 & 0.1489 & 0.3263 & 0.4189 \\
2014 & 0.4884 & 0.8174 & 0.8174 & 0.6033 & 0.7728 & 0.8174 \\
2015 & 0.3865 & 0.3263 & 0.7728 & 0.5637 & 0.6033 & 0.3556 \\
2016 & 0.9540 & 0.5254 & 0.9540 & 0.5254 & 0.9081 & 0.6033 \\
2017 & 0.3556 & 0.0567 & 0.8174 & 0.4884 & 0.2253 & 0.0433 \\
\hline
\end{tabular}

Table 10. Ljung-Box Qtest for style indexes - monthly

\begin{tabular}{llr}
\hline Style & $\mathrm{p}$ & $\mathrm{H}$ \\
\hline Value & 0.0929 & 0 \\
& 0.1019 & 0 \\
Growth & 0.0360 & 0 \\
& 0.0027 & 0 \\
Broad market & 0.3349 & 0 \\
& 0.0423 & 1 \\
\hline
\end{tabular}

Table 11. Ljung-Box Qtest for size indexes - monthly

\begin{tabular}{llr}
\hline Style & $\mathrm{p}$ & $\mathrm{H}$ \\
\hline Large & 0.1505 & 0 \\
& 0.1882 & 0 \\
Medium & 0.0743 & 0 \\
& 0.0317 & 1 \\
Small & 0.3271 & 0 \\
& 0.0072 & 1 \\
\hline
\end{tabular}


Table 12. Ljung-Box Qtest for style indexes - weekly

\begin{tabular}{llr}
\hline Style & $\mathrm{p}$ & $\mathrm{H}$ \\
\hline Value & $1.0 \mathrm{e}-6^{*} 0.4171$ & 1 \\
& 0.0000 & 1 \\
Growth & 0.0000 & 1 \\
& 0.0000 & 1 \\
Broad market & 0.0000 & 1 \\
& 0.0000 & 1 \\
\hline
\end{tabular}

Table 13. Ljung-Box Qtest for size indexes - monthly

\begin{tabular}{llr}
\hline Style & $\mathrm{p}$ & $\mathrm{H}$ \\
\hline Large & 0.0118 & 1 \\
& 0.0000 & 1 \\
Medium & $1.0 \mathrm{e}-13^{*} 0.9703$ & 1 \\
& 0.0000 & 1 \\
Small & $1.0 \mathrm{e}-13 * 0.1485$ & 1 \\
& 0.0000 & 1 \\
\hline
\end{tabular}

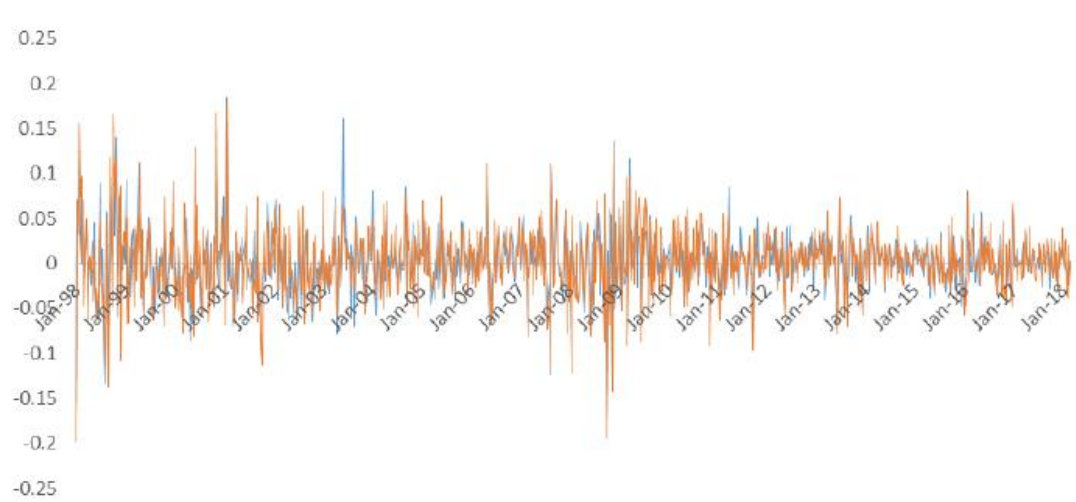

Figure 5. Style indexes returns - weekly

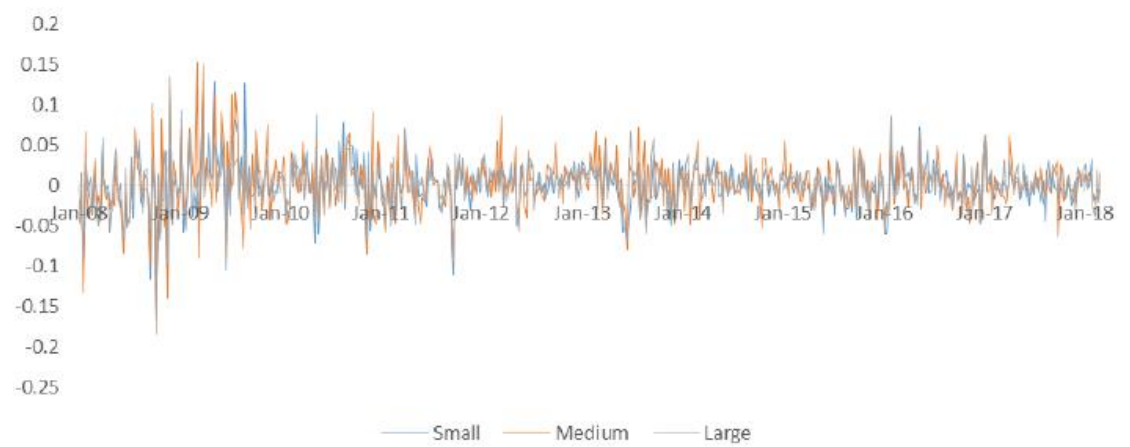

Figure 6. Size indexes returns - weekly

\section{Results}

In the 20 years period from 1998 to 2017 the point estimate of the value index was better than the one from the growth index in only nine years (in 3 of those years the return of the index was negative but value stocks had a 
smaller drop than growth stocks). The results are similar when the risk adjusted returns (via Sharpe ratios) are compares. The time series for this risk adjusted returns is shorter due to data availability (from 2008 to 2017) but there is again no indication of sustained outperformance of value stocks with only in four years out of ten the value index outperforming on a risk adjusted basis. The time series for the size index is shorter than the one for style indexes (from 2008 to 2017). The small size index outperformed the large size index only in five out of the ten years and it only outperformed both the large and midsize indexes in three out of the total ten years. On a risk adjusted basis the results are also similar with the point estimate of the small size index outperforming the large size index in only four of the ten studied years and outperforming both the large and the midsize indexes only in three out of ten years.

The formal Wilcoxon rank sum tests and Kruskal Wallis test (tables 2 to 9) overwhelmingly fail to reject their null hypothesis (of same medians and data coming from the same distributions respectively). The results are consistent when analyzing the entire time series as well as by the vast majority of the years. These results seem to support the idea that there is no statistically significant outperformance of value stocks or small stocks for the period analyzed in the stock market of the Philippines.

The results regarding volatility clustering are more mixed. When using monthly returns there appears to be no volatility clustering for the value or the growth index however when using weekly returns there appear to be volatility clustering for both indexes. The results point towards the existence of volatility clustering for the large, medium and small indexes at a weekly level. When using monthly returns the results are more mixed with no indication of volatility clustering for large stocks and mixed results for the small and midsize index.

Table 14. Performance of value and growth style

\begin{tabular}{lllllllllll}
\hline Year & 1998 & 1999 & 2000 & 2001 & 2002 & 2003 & 2004 & 2005 & 2006 & 2007 \\
\hline Value & $1.9 \%$ & $15.6 \%$ & $-34.8 \%$ & $-11.4 \%$ & $-36.7 \%$ & $46.8 \%$ & $23.7 \%$ & $8.5 \%$ & $44.1 \%$ & $20.3 \%$ \\
Growth & $16.8 \%$ & $-9.2 \%$ & $-25.5 \%$ & $-20.6 \%$ & $-17.9 \%$ & $42.7 \%$ & $27.3 \%$ & $17.7 \%$ & $43.2 \%$ & $12.2 \%$ \\
Market & $5.3 \%$ & $8.8 \%$ & $-30.3 \%$ & $-21.8 \%$ & $-12.8 \%$ & $41.6 \%$ & $26.4 \%$ & $15.0 \%$ & $42.3 \%$ & $21.4 \%$ \\
\hline Year & 2008 & 2009 & 2010 & 2011 & 2012 & 2013 & 2014 & 2015 & 2016 & 2017 \\
\hline Value & $-39.1 \%$ & $44.0 \%$ & $13.9 \%$ & $-3.6 \%$ & $28.7 \%$ & $3.9 \%$ & $20.9 \%$ & $-4.2 \%$ & $-2.0 \%$ & $20.1 \%$ \\
Growth & $-54.7 \%$ & $68.7 \%$ & $33.4 \%$ & $-2.4 \%$ & $41.2 \%$ & $2.9 \%$ & $29.4 \%$ & $-2.4 \%$ & $-3.0 \%$ & $27.5 \%$ \\
Market & $-48.3 \%$ & $63.0 \%$ & $37.6 \%$ & $4.1 \%$ & $33.0 \%$ & $1.3 \%$ & $22.8 \%$ & $-3.9 \%$ & $-1.6 \%$ & $25.1 \%$ \\
\hline
\end{tabular}

Table 15. Sharpe ratios of value and growth style

\begin{tabular}{lllllllllll}
\hline Year & 2008 & 2009 & 2010 & 2011 & 2012 & 2013 & 2014 & 2015 & 2016 & 2017 \\
\hline Value & -1.55 & 2.69 & 0.41 & -0.46 & 2.83 & 0.02 & 1.91 & -0.79 & -0.36 & 1.70 \\
Growth & -2.02 & 2.19 & 0.98 & -0.36 & 2.99 & -0.03 & 2.76 & -0.56 & -0.49 & 2.16 \\
Market & -1.91 & 3.02 & 1.70 & -0.05 & 3.13 & -0.11 & 2.34 & -0.69 & -0.39 & 2.56 \\
\hline
\end{tabular}

Table 16. Performance of style indexes

\begin{tabular}{lllllllllll}
\hline Year & 2008 & 2009 & 2010 & 2011 & 2012 & 2013 & 2014 & 2015 & 2016 & 2017 \\
\hline Small & $-62.3 \%$ & $120.6 \%$ & $74.9 \%$ & $-9.4 \%$ & $36.6 \%$ & $-22.3 \%$ & $28.2 \%$ & $-22.0 \%$ & $15.9 \%$ & $-0.6 \%$ \\
Large & $-41.2 \%$ & $33.6 \%$ & $18.1 \%$ & $-2.6 \%$ & $33.3 \%$ & $-0.1 \%$ & $24.9 \%$ & $-2.9 \%$ & $-2.1 \%$ & $27.0 \%$ \\
Medium & $-56.9 \%$ & $137.7 \%$ & $50.1 \%$ & $-7.1 \%$ & $39.0 \%$ & $34.9 \%$ & $22.1 \%$ & $-7.3 \%$ & $-4.4 \%$ & $9.7 \%$ \\
\hline
\end{tabular}

Table 17. Sharpe ratios of size style

\begin{tabular}{lllllllllll}
\hline Year & 2008 & 2009 & 2010 & 2011 & 2012 & 2013 & 2014 & 2015 & 2016 & 2017 \\
\hline Small & -2.32 & 3.18 & 2.58 & -0.55 & 3.12 & -0.93 & 2.55 & -1.57 & 0.49 & -0.56 \\
Large & -1.57 & 1.62 & 0.54 & -0.40 & 2.86 & -0.17 & 2.57 & -0.71 & -0.41 & 2.45 \\
Medium & -2.31 & 3.37 & 1.78 & -0.47 & 2.06 & 1.98 & 1.14 & -0.71 & -0.46 & 0.32 \\
\hline
\end{tabular}




\section{Discussion}

There is no obvious outperformance of value stocks or small size stocks in the case of the Philippines over the recent years. These results were consistent for the two decades period (1998-2017) used for the style indexes as well as during each of those years individually. The time series for the size indexes is shorter, due to data availability (from 2008 to 2017) but the results were equally consistent. In both cases the analysis was performed using the entire data series as well as each year independently. This is a surprising result considering that many articles have found that value stocks and small size stocks outperform in many other countries. The stock market of the Philippines presents many peculiarities that perhaps cause this difference in behavior with the stock markets of other countries.

Using weekly returns it appears that value, growth as well as small, midsize and large size equity indexes in the Philippines present volatility clustering. The results are much more mixed when the monthly returns are used instead of the weekly returns.

\section{References}

Abola, V. (2016). Capital market development in the Philippines. Nomura Journal of Asian Capital Markets, 1.

Banz, R. (1981). The relationship between return and market value of common stocks. Journal of Financial Economics, 9. https://doi.org/10.1016/0304-405X(81)90018-0

Basu, S. (1997). Investment performance of common stocks in relation to their price-earnings ratio: a test of the efficient market hypothesis. Journal of Finance, 32.

Bautista, C. (2010). Stock market volatility in the Philippines. Applied Economic Letter, 10.

BSP. (2015). 2015 annual report. Bangko Sentral ng Pilipinas. Retrieved from http://www.bsp.gov.ph/downloads/publications/2015/annrep2015.pdf

Chua, C. (2014). Assessment on the use of online trading portal of some investors in the Philippines. Journal of Industrial and Intelligent Information, 2(3). https://doi.org/10.12720/jiii.2.3.222-227

Cielito, H., \& Roehlano, B. (2005). Philippine agriculture over the years: Performance, policies and pitfalls. Conference of Policies to Strengthen Productivity in the Philippines. (ASEM).

DOF. (2017). Department of Finance of the Philippines. The tax reform for acceleration and inclusion (TRAIN) act. Retrieved from https://www.dof.gov.ph/index.php/ra-10963-train-law-and-veto-message-of-the-president/

Ducanes, G. (2015). The welfare impact of overseas migration on Philippine households: Analysis using panel data. Asian and Pacific Migration Journal, 24.

Fukuoka, F. (2010). Population growth and economic developments: empirical evidence from the Philippines. Philippine Journal of Developments, 68.

Galido, A. (2013). Natural disasters and the Philippine stock exchange index: a GARCH-M analysis. DLSU Business \& Economics Review, 22. Retrieved from http://www.sec.gov.ph/

Graham. B. (1949). The Intelligent Investor. Harper \& Brothers.

Habaradas, R. (2013). Umali Mar. The microfinance industry in the Philippines: striving for financial inclusion in the midst of growth. CDBRD working paper.

Kalayaan, C. (2016). Superstition in the Philippine Stock market. Review of Integrative Business and Economics Research, 5(2).

Lida, N. (2016). Trade openness and stock market volatility in the ASEAN-5 countries: New evidence using SUR. Investment Analysts Journal, 45(3).

Lim, J. (2008). Central banking in the Philippines: from inflation targeting to financing development. International Review of Applied Economics, 22. https://doi.org/10.1080/02692170701880791

Llanto, G. (2015). Financial inclusion, education and regulation in the Philippines. ADBI working paper series, No. 541 .

MT. (2017). The Manila Times. Philippines Stock Exchange: PSE rejects higher stock transaction tax. Retrieved from

http://www.4-traders.com/PHILIPPINE-STOCK-EXCHANGE-6496666/news/Philippine-Stock-Exchange-PSE -rejects-higher-stock-transaction-tax-25670205/

Ofreneo, R. (2015). Growth and employment in the de-industrializing Philippines. Journal of the Asia Pacific 
Economy, 25. https://doi.org/10.1080/13547860.2014.974335

PSA. (2018). Philippine Statistics Authority. Economic time series. Retrieved from http://psa.gov.ph/nap-press-release/data-charts

Regina, G. C., Padilla, S., \& Visda, M. F. (2013). Philippine stock market in perspective. 12th National convention on statistics (NCS). Retrieved from http://nap.psa.gov.ph/ncs/12thncs/papers/INVITED/IPS-21\%20Finance\%20Statistics/IPS-21_3_Philippine\%20 Stock\%20Market\%20in\%20Perspective.pdf

Renato, R. (2009). Determinants of overseas Filipino worker (OFW) remittances. UP school discussion papers.

RP. (2014). Rappler. PSE taps NASDAQ for trading technology. Retrieved from https://www.rappler.com/business/industries/215-tech-biz/62101-pse-nasdaq-trading-tech

SEC. (2018). The Securities and Exchange Commission of the Philippines (SEC). Retrieved from http://www.sec.gov.ph/

Shelor, A. (1989). Gaining from loss: property-liability insurer stocks values in the aftermath of the 1989 California earthquake. Journal of Risk and Insurance, 59.

Su, D., \& Holifena, D. (2014). Monetary policy and stock market movement in the Philippines: a structural vector autoregression approach. Asia Pacific Business \& Economics Perspectives, 2.

Sum, V. (2013). The ASEAN stock market performance and economic policy uncertainty in the United States. Economic Paper: A Journal of Applied Economics and Policy, 32.

WB (World Bank). (2014). Philippine economic update: Pursuing inclusive growth through sustainable reconstruction and job creation. Retrieved from http://www.worldbank.org/content/dam/Worldbank/document/EAP/Philippines/Philippine\%20Economic\%20Up date\%20March\%202014.pdf

Wu, K. J., Lu, C. C., Haruriro, J., \& Irell, P. (2012). Interrelationship between Philippine Stock Exchange index and USD exchange rate. Procedia - Social and behavioral sciences, 40. https://doi.org/10.1016/j.sbspro.2012.03.264 